\title{
How does Chinese loess become magnetized?
}

\author{
Xiang Zhao, Andrew P. Roberts* \\ National Oceanography Centre, University of Southampton, European Way, Southampton SO14 3ZH, UK
}

\section{A R T I C L E I N F O}

\section{Article history:}

Received 5 September 2009

Received in revised form 13 January 2010

Accepted 18 January 2010

Available online 12 February 2010

Editor: P. DeMenocal

\section{Keywords:}

Chinese loess

paleomagnetism

depositional remanent magnetization (DRM)

post-depositional remanent magnetization (PDRM)

chemical remanent magnetization (CRM)

inclination error

\begin{abstract}
A B S T R A C T
Despite nearly three decades of paleomagnetic research on the extensive Chinese loess deposits, a convincing explanation has yet to be developed for how Chinese loess becomes magnetized. To address this problem, we conducted re-deposition experiments using weakly consolidated Holocene Chinese loess that was disaggregated in the laboratory, and compare our results with published paleomagnetic data. We simulated a depositional remanent magnetization (DRM) associated with dry deposition of eolian sediments, and a post-depositional remanent magnetization (PDRM) in which the sediment was water-saturated after deposition. The simulated DRM faithfully records the declination of the applied field, but with systematic inclination flattening. Addition of minor water slightly improves recording of the applied field, but inclination flattening persists. Reliable recording of the applied field occurs for PDRM simulation in watersaturated sediment. Our synthesis of paleomagnetic data from Chinese loess indicates that time-averaged paleomagnetic directions are often indistinguishable from the expected geocentric axial dipole (GAD) field, but in many cases inclinations are shallower than for a GAD field. We conclude that the Chinese loess is magnetized by a combination of DRM and PDRM mechanisms, with water content providing the dominant control on which mechanism aligns the detrital mineral fraction. Where pedogenesis causes neoformation of magnetic minerals, an additional chemical remanent magnetization (CRM) will occur. The magnetization of Chinese loess therefore appears to be controlled by a complex time-varying combination of DRM, PDRM and CRM mechanisms.
\end{abstract}

(C) 2010 Elsevier B.V. All rights reserved.

\section{Introduction}

Vast expanses $\left(\sim 500,000 \mathrm{~km}^{2}\right)$ of thick, ancient wind-blown dust deposits are preserved on the Chinese Loess Plateau in central China. These deposits represent one of the world's most outstanding terrestrial archives of paleoclimate change. Chinese loess sequences range between $\sim 100$ and $300 \mathrm{~m}$ in thickness and record aridity in desertified source regions in northwestern China and Mongolia during glacial periods, while intercalated paleosols reflect intensified summer monsoon conditions that supported soil formation during interglacial periods. These climate changes are recorded over the last 2.6 million years (Ma) in loess/paleosol sequences (Heller and Liu, 1982, 1984; Liu et al., 1988; Rutter et al., 1990) and back to 22 Ma in the underlying red clay sequences (Guo et al., 2002). High loess accumulation rates preserve paleoclimate signals that can be analysed at high resolution, including millennial-scale climate changes (e.g., Liu et al., 2005).

Paleomagnetic studies have proved crucial in establishing the chronology of paleoclimate variations in Chinese loess sequences (e.g., Heller and Liu, 1982, 1984; Liu et al., 1988; Rutter et al., 1990). Identification of the positions of geomagnetic reversals over the past 2.6 Ma enabled correlation of magnetic susceptibility profiles to the

\footnotetext{
* Corresponding author. Now at: Research School of Earth Sciences, The Australian National University, Canberra, ACT 0200, Australia. Tel.: +61 261252487.

E-mail addresses: arob@noc.soton.ac.uk, andrew.roberts@anu.edu.au (A.P. Roberts).
}

marine $\delta^{18} \mathrm{O}$ record (Kukla et al., 1988). Magnetic susceptibility peaks occur within paleosols as a result of magnetite/maghemite formation during pedogenesis (e.g., Zhou et al., 1990); the intervening loess units have much lower magnetic susceptibilities. Despite this first-order success in establishing the loess chronology, which has been assisted by orbital tuning of paleoclimatically sensitive parameters such as magnetic susceptibility (Heslop et al., 2000), a major chronological conundrum has persisted. The last major geomagnetic reversal (Matuyama-Brunhes boundary) is widely recorded in glacial deposits in the Chinese loess, whereas it is located in interglacial deposits in marine sediments (e.g., Tauxe et al., 1996; Zhou and Shackleton, 1999). This conundrum has made it difficult to correlate paleoclimate signals in loess with those in other archives and to establish phase relationships between the respective signals. This chronological problem has been resolved by Wang et al. (2006) and Liu et al. (2008) who demonstrated that parameters such as magnetic susceptibility are too sensitive to local variations in rainfall and pedogenesis, which means that they can provide misleading information concerning the positions of boundaries between glacials and interglacials. In contrast, quartz grain size is insensitive to pedogenic alteration and is a useful parameter for determining the true position of magnetic polarity boundaries with respect to paleoclimatic boundaries. Liu et al. (2008) demonstrated that there is no offset in the position of the Matuyama-Brunhes boundary between marine and Chinese loess sequences if quartz grain size is used as a paleoclimate proxy for the Chinese loess. They thereby 
demonstrated that there is no need to invoke a deep post-depositional remanent magnetization (PDRM) lock-in (of up to $3 \mathrm{~m}$ ) to explain paleomagnetic observations from the Chinese Loess Plateau (cf. Tauxe et al., 1996; Zhou and Shackleton, 1999).

Despite recent resolution of this long-standing conundrum, and despite the fact that paleomagnetic reversal stratigraphies have been successfully developed in Chinese loess sequences for nearly 3 decades since the pioneering work of Heller and Liu (1982), the mechanism by which Chinese loess acquires its paleomagnetic signal is still not understood. Part of the problem lies with the perception that there are significant delays in remanence acquisition in Chinese loess (of 2-3 $\mathrm{m}$ or 20-30 kyr), as discussed above (e.g., Tauxe et al., 1996; Zhou and Shackleton, 1999; Heslop et al., 2000). This conclusion has been difficult to reconcile with the observation that the Chinese loess often records high-frequency geomagnetic signals, including excursions (e.g., Pan et al., 2002; Yang et al., 2007; Zhu et al., 2007), which would not be possible with deep PDRM lock-in (cf. Roberts and Winklhofer, 2004). In order to account for the previously hypothesized large downward shift of geomagnetic reversal boundaries in Chinese loess sequences (e.g., Tauxe et al., 1996; Zhou and Shackleton, 1999; Heslop et al., 2000), while enabling recording of high-frequency geomagnetic features (e.g., Pan et al., 2002), Spassov et al. (2003) proposed a composite model in which the natural remanent magnetization (NRM) is a shallow PDRM that is augmented by a later pedogenic chemical remanent magnetization (CRM). Liu et al. (2008) conclusively removed the basis for invoking deep PDRM and CRM acquisition, although this is not to say that CRM does not remain a valid mechanism for NRM acquisition, particularly at shallow depths within paleosols where magnetite and maghemite are known to grow through the stable single domain blocking volume. Nevertheless, fundamental questions remain about the mechanism(s) by which loess records geomagnetic signals. If the NRM is acquired at shallow depths, is it acquired through a detrital remanent magnetization (DRM) or is it a PDRM or a CRM or is it a composite of several mechanisms? Constraining these questions is fundamental to the interpretation of paleomagnetic data from the Chinese Loess Plateau. Re-deposition experiments are therefore needed to help us understand how Chinese loess becomes magnetized. We know of only one such preliminary experiment for the Chinese loess (McIntosh, 1993). We report results of more comprehensive re-deposition experiments in this paper.

\section{Methods}

In order to simulate the loess deposition processes described by Liu et al. (1985), re-deposition experiments were performed on weakly consolidated Holocene loess sediments from Yuanbao, Gansu province, western Chinese Loess Plateau. The loess was disaggregated to produce a uniformly fine-grained dust for the experiments. The experiments were performed in a specially constructed eolian dust deposition simulator (Fig. 1). The device is a sealed Perspex box, which is fed by an inlet pipe into the side of the unit, with an exhaust at the top of the box. Dry sediment was delivered into the inlet pipe of

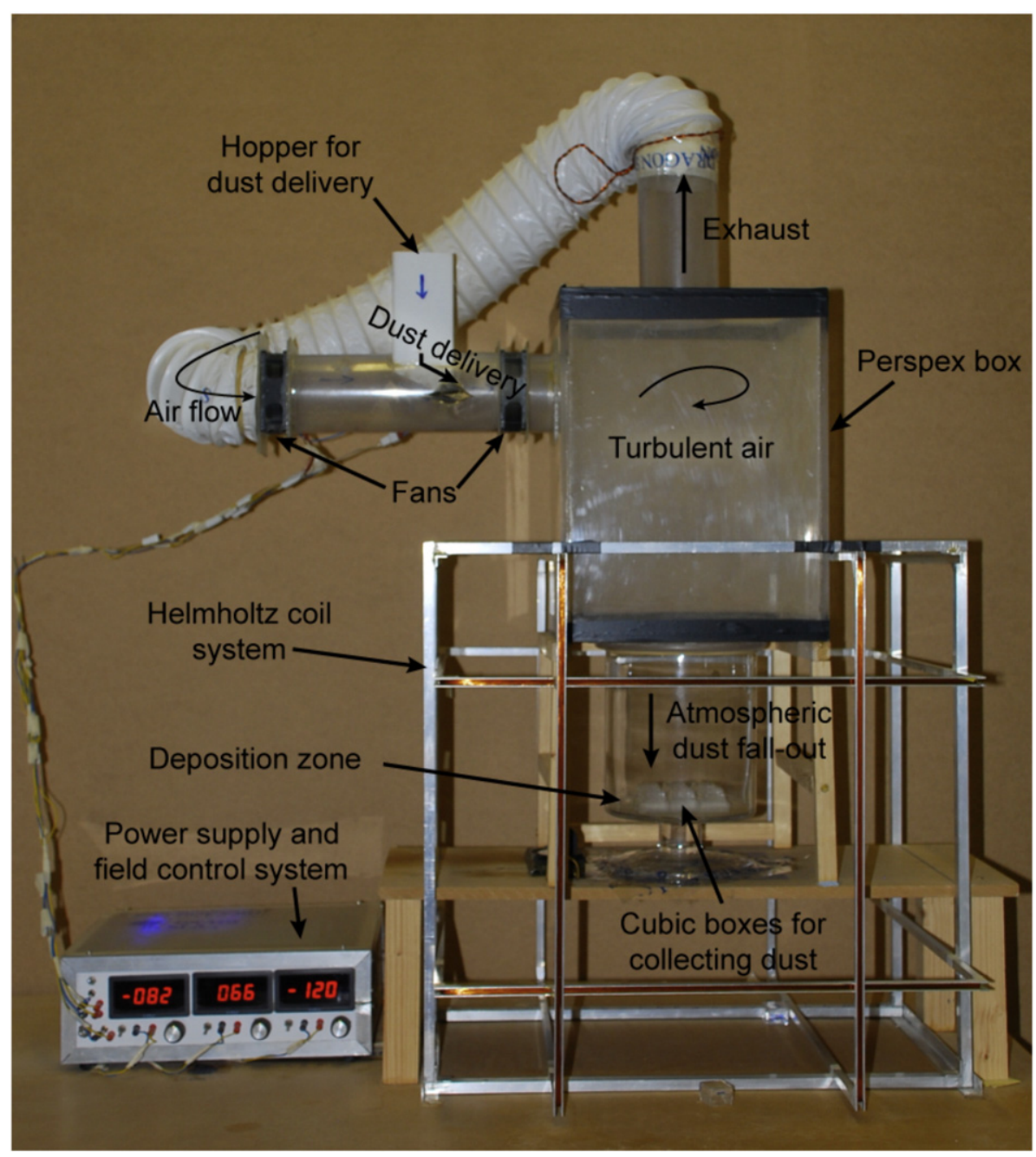

Fig. 1. Photograph of the eolian dust deposition simulator used for the experiments reported in this paper. See text for explanation. 
the eolian deposition simulator via a hopper. A steady flow of sediment was released into the inlet pipe by use of a motor-controlled roller at the bottom of the hopper. When the sediment falls from the hopper into the underlying pipe, fans blow the dust into the Perspex box, under which is situated a deposition chamber. This chamber is placed within a set of three mutually orthogonal Helmholtz coils, each of which can be adjusted independently. Nine empty plastic paleomagnetic sample cubes were placed at the base of the chamber; this deposition zone lies at the centre of the Helmholtz coil system to ensure precise field control in the vicinity of the plastic cubes. An average of $4.0 \mathrm{~g}$ of sediment was deposited in each cube per experiment (dry sample masses ranged from 1.6 to $7.4 \mathrm{~g}$ ). The sediment was deposited into the plastic cubes using a range of field directions. The field intensity was maintained for all experiments at $50 \mu \mathrm{T}$, which is a typical value for the present-day geomagnetic field on the Chinese Loess Plateau. Deposition was usually allowed to proceed for 3-4h for each experiment. Upon completion of the experiment, the field was switched off and the cubes were removed from the chamber and were taken into a magnetically shielded laboratory at the National Oceanography Centre, Southampton (NOCS) for measurement of the NRM. Magnetic measurements were made using a 2-G Enterprises superconducting rock magnetometer. After measuring (and sometimes repeatedly remeasuring) the initial NRM of the re-deposited sediments, static 3-axis stepwise alternating field (AF) demagnetization was performed using applied fields of $2.5,5,7.5,10,12.5,15,20,25,30,40,50,60,70,80$, and $100 \mathrm{mT}$ on an AF demagnetization system that is arranged in-line with the magnetometer. AF demagnetization was conducted to assess the stability of the magnetizations. Principal component analysis (PCA) was used to determine the characteristic remanent magnetization (ChRM) from a best fit through the stepwise AF demagnetization data (Kirschvink, 1980). The uncertainty associated with this determination is given by the maximum angular deviation (MAD). AF demagnetization was conducted many times on the studied sediments, both before the original sediment was disaggregated and after each re-deposition experiment. The sediments have uniform magnetic properties, as indicated by the virtually identical coercivity spectra for all demagnetization runs.

A series of re-deposition experiments was carried out. The first involved dry deposition to simulate a pure eolian DRM and to assess its recording fidelity for a range of field settings. The second set of experiments involved dry deposition, after which the Perspex box was removed and water was gently sprayed through a fine nozzle from a spray bottle to provide a small amount of moisture to the deposited sediment. The water content was small and was not determined for this set of experiments. The field remained switched on during water spraying. Minor moisture was added to assess whether it enabled magnetic grain remobilization after deposition to improve recording efficiency. The third set of experiments involved dry deposition in zero-field. After deposition, the samples were measured in the magnetometer and then weighed. Water was then added to the samples so that the deposited sediments were water saturated. The samples were measured in the magnetometer again and were weighed again to allow calculation of the water content. Water content was estimated following the definition of Verosub et al. (1979) where: $\mathrm{H}_{2} \mathrm{O} \%=\left(\left(\right.\right.$ Mass $_{\text {total }}-$ Mass $\left._{\text {dry }}\right) /$ Mass $\left._{\text {dry }}\right) \times 100 \%$. In many cases, water ponded above the sediment surface in the plastic cubes used to hold the samples, so $\mathrm{H}_{2} \mathrm{O}$ \% is not a true measure of water content in relation to sediment pore space. After weighing, the cubes were returned to the deposition chamber and the field was switched on. Covers were placed on top of the plastic cubes to maintain humidity and to minimize evaporation for either 12 or $24 \mathrm{~h}$, respectively. At the end of this period, the samples were allowed to dry within the same field. Drying took 2-3 days. Any stable remanence produced is likely to be a PDRM because the water content was sufficiently high that any depositional alignment was probably lost after addition of water. When dry, the samples were measured in the magnetometer and were subjected to progressive AF demagnetization. The above procedure for PDRM simulation is similar to that employed by Irving and Major (1964). The samples were then subjected to progressive acquisition of an anhysteretic remanent magnetization (ARM) with a dc bias field of $0.05 \mathrm{mT}$ and a progressively increasing AF using applied fields of $2.5,5,7.5,10,12.5$, $15,20,25,30,40,50,60,70,80$, and $100 \mathrm{mT}$. The ARM was subjected to stepwise AF demagnetization using the same sequence of applied fields.

\section{Results}

\subsection{NRM recording fidelity from re-deposition experiments}

Simulation of a pure eolian DRM was performed in 18 dry deposition experiment runs ( 9 samples per run). Dry deposition enables
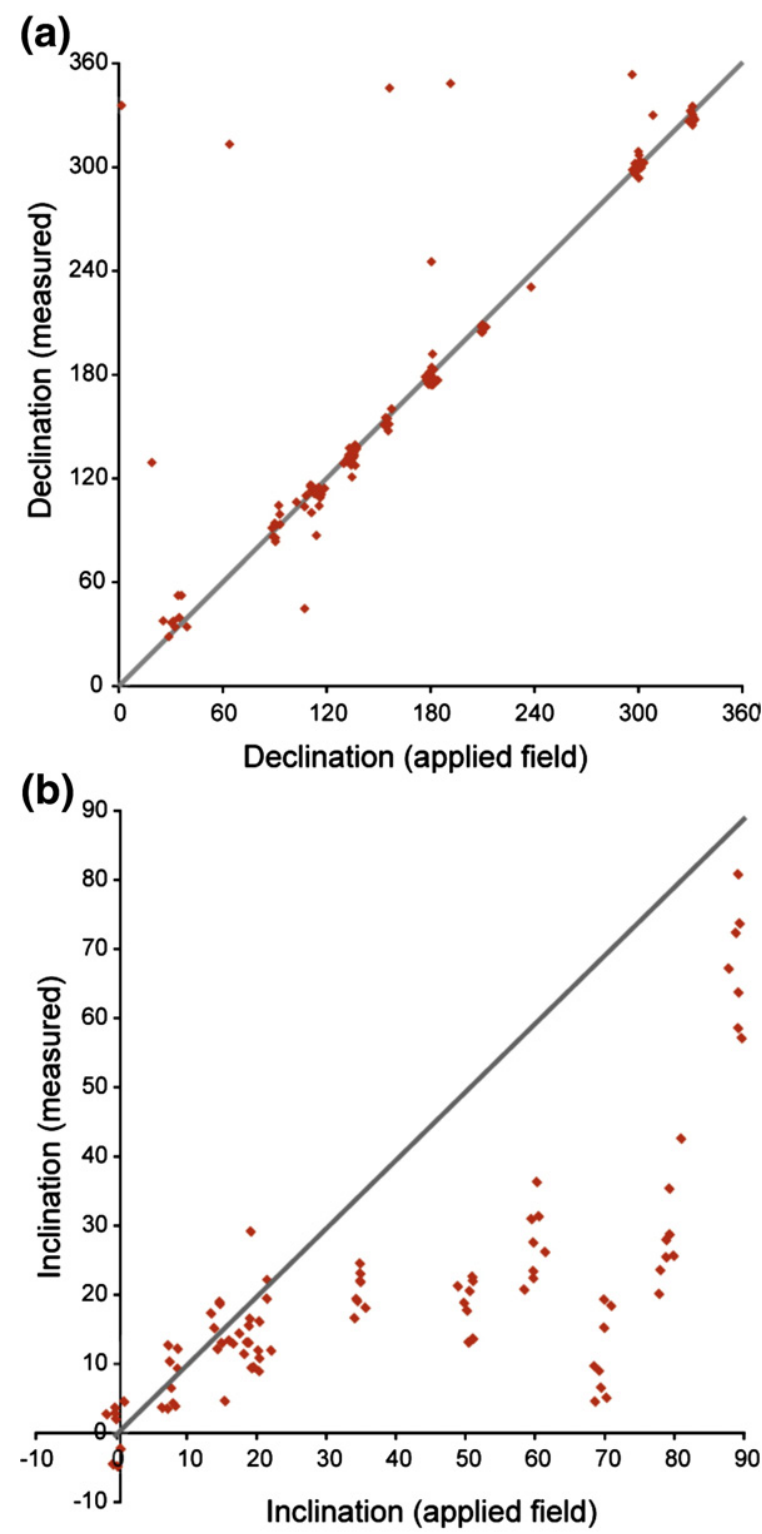

Fig. 2. Recording fidelity of a DRM produced via dry deposition in the eolian dust simulator (Fig. 1). (a) Measured NRM declination for re-deposited samples plotted versus the applied ambient field declination. (b) Measured NRM inclination for redeposited samples plotted versus the applied ambient field inclination. The declination data that lie the furthest off the 1:1 line correspond to the steepest inclinations. A significant inclination error is also observed. See text for discussion. 
(a)

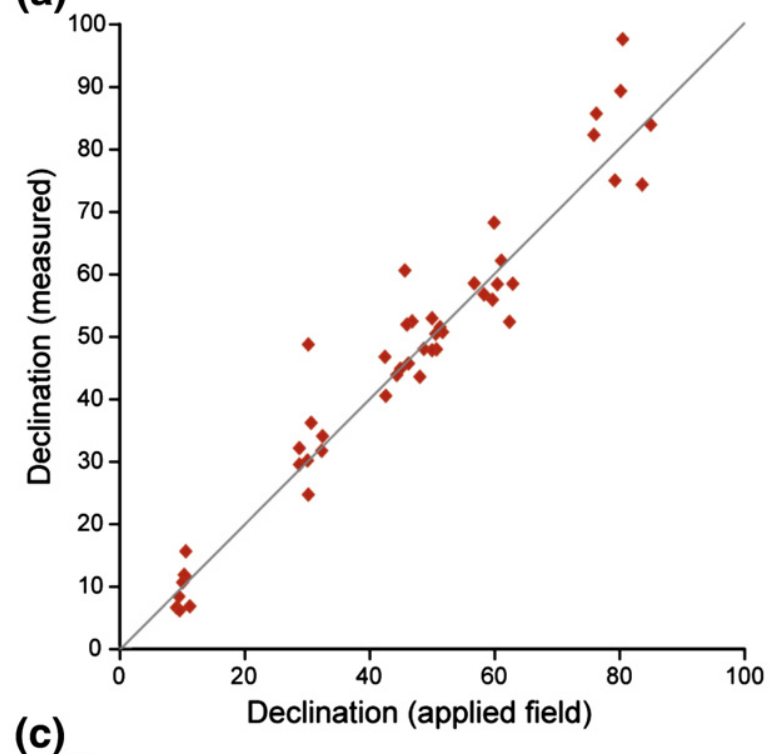

(c)

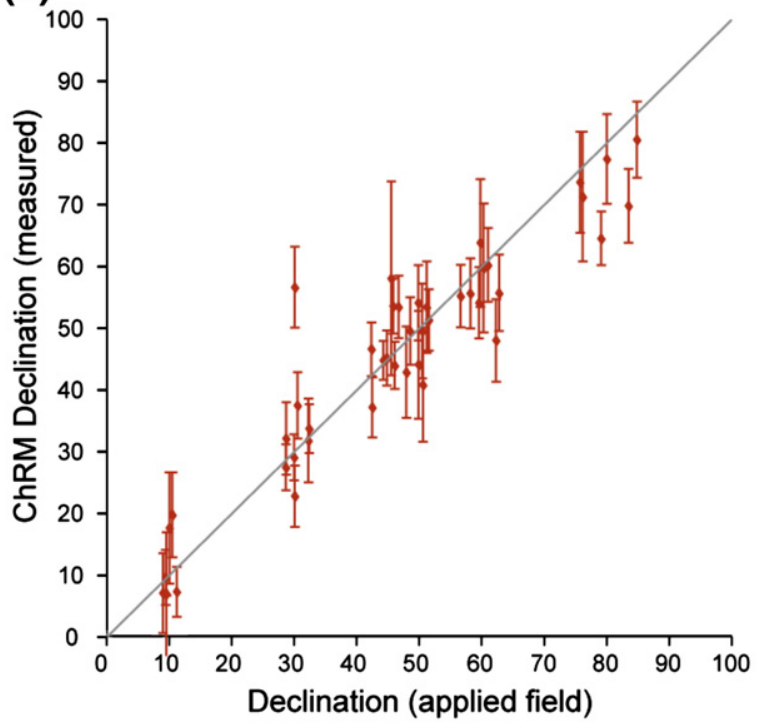

(b)
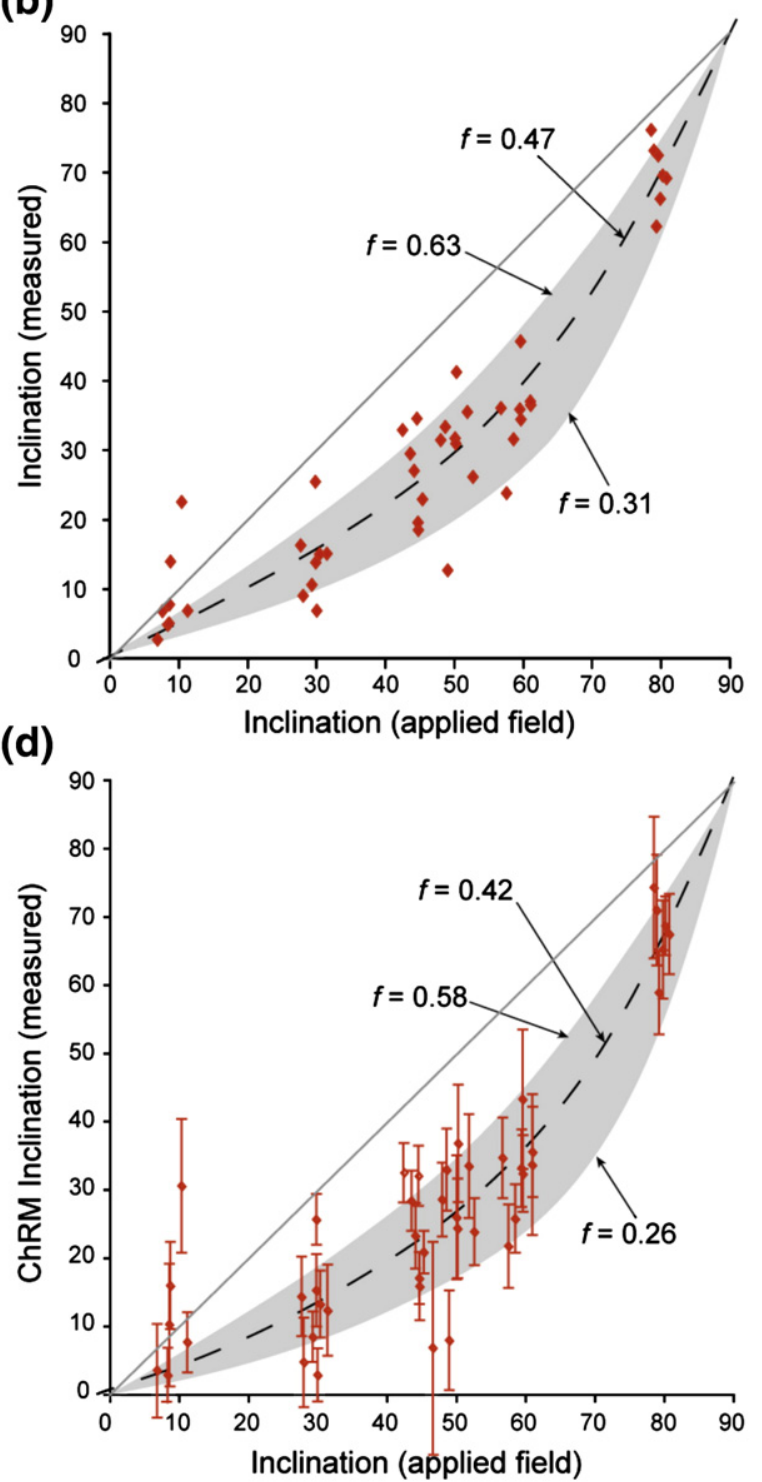

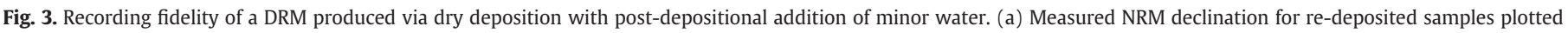

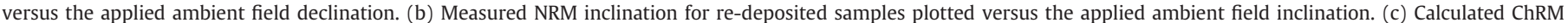

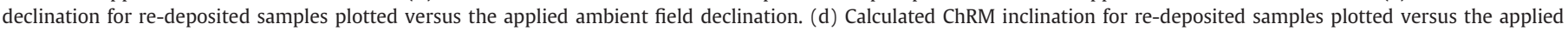

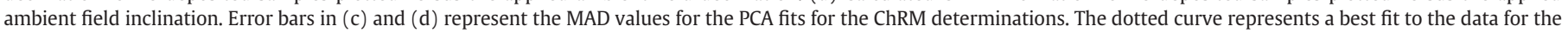
inclination error formula of King (1955): $\tan I_{o}=f \tan I_{f}$ (see text for discussion), with the $1 \sigma$ range indicated by grey shading.

faithful recording of the declination of the ambient field, except when the inclination is steep (Fig. 2a). As expected for steep fields, any misalignment of particles away from the vertical produces declination scatter. Nevertheless, apart from this case, the declination of the ambient field is well recorded. In contrast, the measured inclinations for the re-deposited loess are systematically shallow (Fig. 2b).

A second set of dry deposition experiments was undertaken (6 batches of 9 samples) to check whether addition of minor moisture could cause post-depositional realignment of particles to improve the DRM recording fidelity. With addition of minor moisture, the NRM (Fig. 3a) and ChRM (Fig. 3c) continue to record accurately the declination of the applied field. However, systematic inclination shallowing continues to be observed for both the NRM (Fig. 3b) and ChRM (Fig. 3d). Addition of minor water therefore does not enable significant post-depositional realignment of magnetic particles (Fig. 3), although the observed inclination shallowing is less severe than in dry deposition experiments (Fig. 2).
Despite the first-order similarity between the dry re-deposition experiments and those with minor added water (Figs. 2 and 3), AF demagnetization results indicate a significant difference in the quality of the recorded magnetizations (Fig. 4). Vector demagnetization diagrams for samples from the two sets of experiments are different, with the samples from the dry re-deposition experiments (with no added water) having less stable magnetizations. Even without demagnetization, these samples undergo a time-dependent exponential decay of magnetization (Fig. 4a). This decay is less evident for samples with minor added water (Fig. 4b) and it is absent for the PDRM experiment (Fig. 4c). The loess sediment used for the experiments has consistently uniform magnetic properties, which precludes a viscous origin for the magnetization decay. This decay appears to be due to progressive physical randomization of particles resulting from vibrations associated with movement of the sample in and out of the magnetometer for the repeated NRM measurements. The fact that this decay is much less evident for samples with minor added water 
(a)
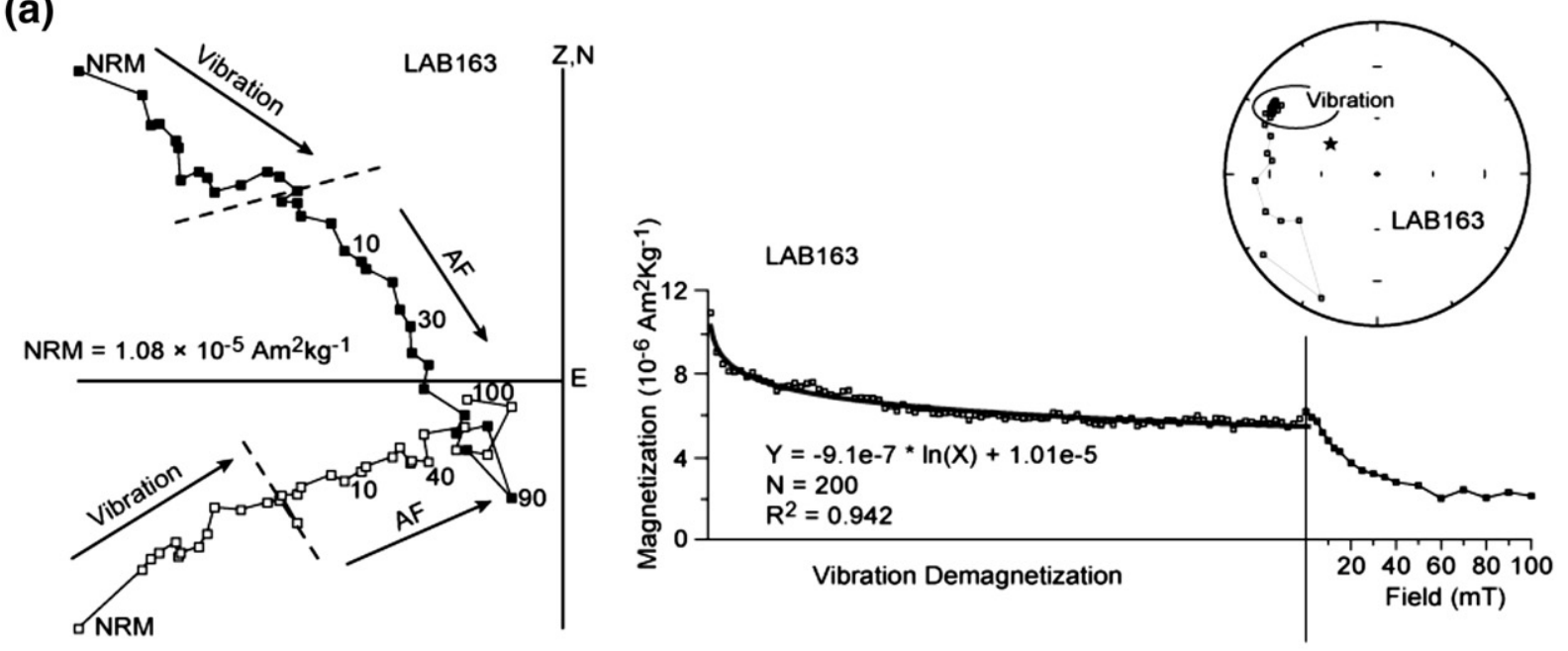

(b)
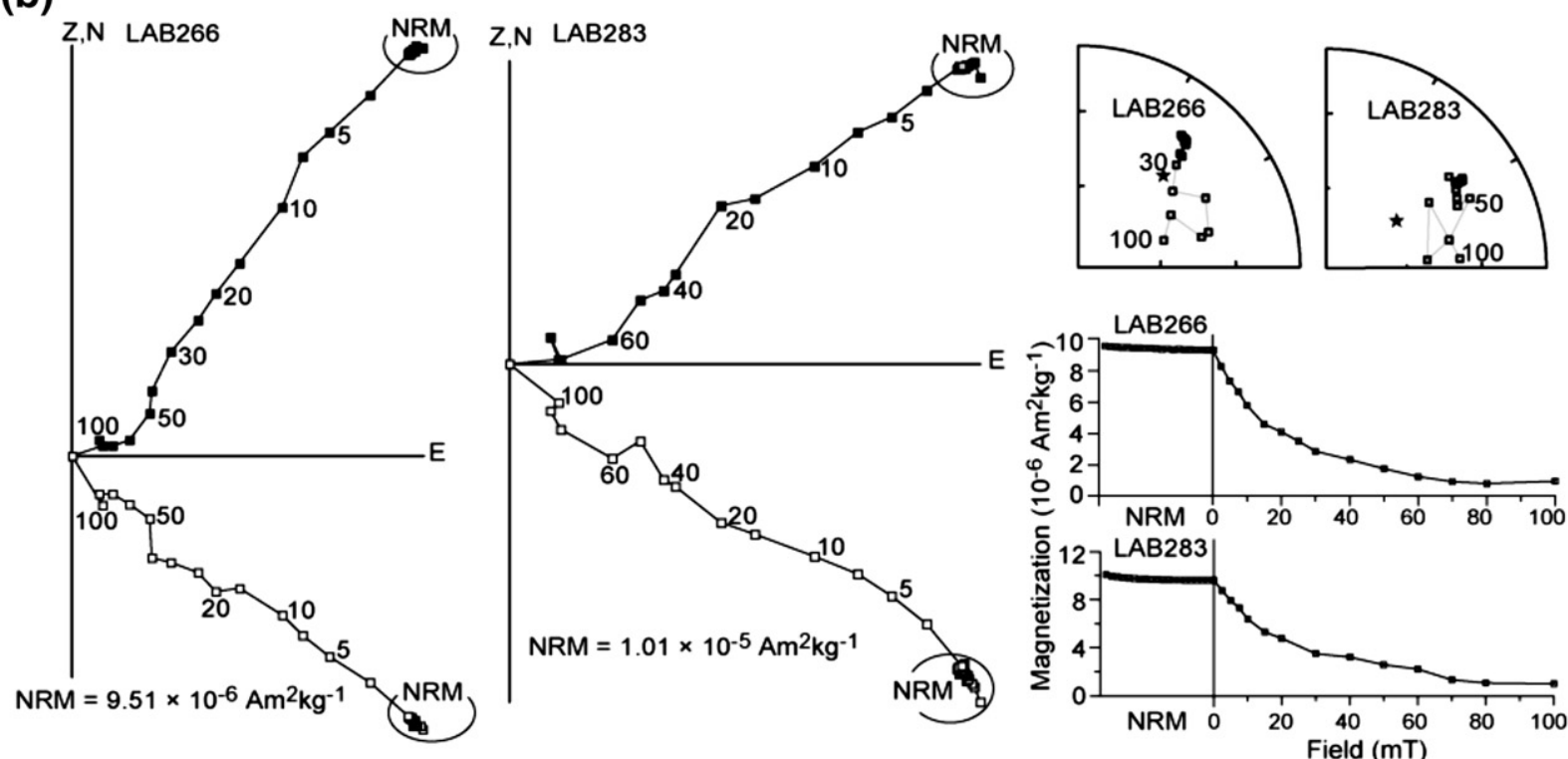

(c)
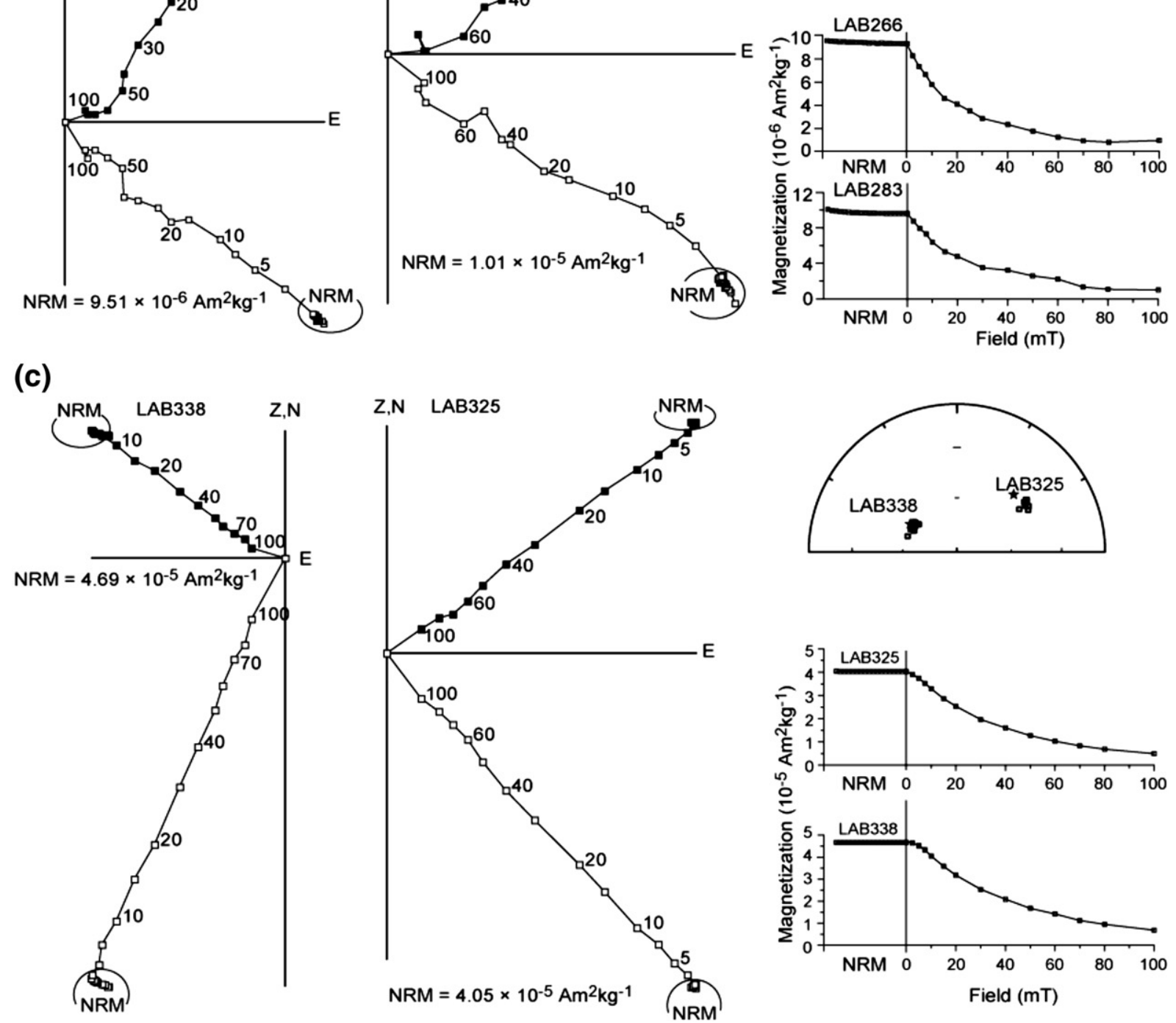
Table 1

Remanence intensities for data from natural samples from Yuanbao and for redeposition experiments using the same sediments.

\begin{tabular}{|c|c|c|c|c|c|c|}
\hline \multirow[t]{2}{*}{ Sample type } & \multirow[t]{2}{*}{ Remanence type } & \multicolumn{4}{|c|}{ Remanence intensity $\left(\mathrm{Am}^{2} \mathrm{~kg}^{-1}\right)$} & \multirow{2}{*}{$\begin{array}{l}\text { Number of } \\
\text { samples }\end{array}$} \\
\hline & & Maximum & Minimum & Mean & $\mathrm{SD}^{\mathrm{a}}$ & \\
\hline Natural Holocene discrete samples ${ }^{\mathrm{b}}$ & NRM & $6.60 \mathrm{E}-06$ & $4.78 \mathrm{E}-06$ & $5.86 \mathrm{E}-06$ & $4.05 \mathrm{E}-07$ & 8 \\
\hline Natural Holocene U-channel sample ${ }^{c}$ & NRM & $5.89 \mathrm{E}-06$ & $2.45 \mathrm{E}-06$ & 3.43E-06 & 4.02E-07 & 122 \\
\hline Natural L1 U-channel samples ${ }^{\mathrm{d}}$ & NRM & 1.17E-05 & $1.71 \mathrm{E}-06$ & 5.19E-06 & $1.18 \mathrm{E}-06$ & 1345 \\
\hline Dry re-deposition ${ }^{\mathrm{e}}$ & DRM & $2.52 \mathrm{E}-05$ & 4.45E-07 & $9.21 \mathrm{E}-06$ & 4.27E-06 & 159 \\
\hline Minor added water after re-deposition ${ }^{\mathrm{f}}$ & DRM & $1.97 \mathrm{E}-05$ & $6.44 \mathrm{E}-06$ & $1.24 \mathrm{E}-05$ & $2.71 \mathrm{E}-06$ & 48 \\
\hline Water saturated after re-deposition ${ }^{g}$ & PDRM & $5.07 \mathrm{E}-05$ & $1.05 \mathrm{E}-05$ & $3.14 \mathrm{E}-05$ & $7.38 \mathrm{E}-06$ & 75 \\
\hline Natural Holocene discrete samples ${ }^{\mathrm{b}}$ & ARM & 3.39E-05 & 2.71E-05 & $3.08 \mathrm{E}-05$ & 2.03E-06 & 8 \\
\hline Natural Holocene U-channel sample ${ }^{c}$ & ARM & $3.98 \mathrm{E}-05$ & $2.44 \mathrm{E}-05$ & $2.97 \mathrm{E}-05$ & $2.80 \mathrm{E}-06$ & 122 \\
\hline Natural L1 U-channel samples ${ }^{\mathrm{d}}$ & ARM & $2.53 \mathrm{E}-05$ & $1.17 \mathrm{E}-06$ & $1.78 \mathrm{E}-05$ & $1.37 \mathrm{E}-05$ & 1345 \\
\hline Water saturated PDRM samples ${ }^{g}$ & ARM & 3.57E-05 & $2.51 \mathrm{E}-05$ & $3.10 \mathrm{E}-05$ & $2.00 \mathrm{E}-06$ & 75 \\
\hline Natural Holocene discrete samples ${ }^{\mathrm{b}}$ & NRM/ARM & 0.21 & 0.16 & 0.19 & 0.01 & 8 \\
\hline Natural Holocene U-channel sample ${ }^{c}$ & NRM/ARM & 0.15 & 0.08 & 0.12 & 0.02 & 122 \\
\hline Natural L1 U-channel samples ${ }^{\mathrm{d}}$ & NRM/ARM & 0.65 & 0.13 & 0.29 & 0.06 & 1345 \\
\hline
\end{tabular}

a $\mathrm{SD}=$ standard deviation.

b Results from 8 discrete samples from the Holocene loess section at Yuanbao (i.e., the parent material for the re-deposition experiments).

c Results from a single U-channel sample (length of $1.22 \mathrm{~m}$ ) from the Holocene loess section at Yuanbao (parent material).

d Results from U-channel samples (length of $13.45 \mathrm{~m}$ ) from pedogenically unaltered L1 unit at Yuanbao.

e Results from 18 batches of 9 samples $(N=162)$; 3 samples were destroyed prior to measurement to give $N=159$.

${ }^{f}$ Results from 6 batches of 9 samples $(N=54) ; 6$ samples were destroyed prior to measurement to give $N=48$.

g Results from 9 batches of 9 samples $(N=81) ; 6$ samples were destroyed prior to measurement to give $N=75$.

indicates that the water has provided some stabilization against vibration-related particle movement. The time-dependent magnetization decay for the pure DRM is probably not geologically meaningful because the particles will be fixed in position through compaction (and possibly cementation). Nevertheless, even though the recorded inclinations are systematically shallow for both sets of DRM experiments (Figs. 2 and 3), the recorded ChRM is more stable even with minor added water (Fig. 4b). Likewise, the DRM intensity is marginally higher and less variable for the experiments with minor added water (Table 1).

The third set of re-deposition experiments was intended to simulate a PDRM. Initial re-deposition in zero-field produced a weak remanence that became substantially stronger when the sample was water-saturated and placed in a 50- $\mu$ T field. At high water contents, the sediment becomes a slurry, and there is little impediment to postdepositional realignment of the magnetic particles by the ambient field. When the water-saturated samples are dried, the recording fidelity of the ambient field is much superior (Figs. 4 and 5; Table 1 ) to samples produced by dry deposition (Figs. 2-4). The declinations for 9 batches of 9 samples are tightly grouped (Fig. 5a). Despite data scatter, there is no systematic inclination shallowing (Fig. 5b).

Water content has a significant effect on magnetic recording fidelity in our experiments. This is evident in the marked difference between the DRM (Figs. 2 and 3) and PDRM (Fig. 5) results, respectively, as well as in the ChRM stability and remanence intensity for each type of magnetization (Fig. 4; Table 1). This difference is reflected in the size of the error bars (which represent MAD values from the respective PCA fits for the ChRM determinations) in Figs. 3 and 5, respectively (note the different declination ranges of these figures). We therefore present additional results to demonstrate the effect of water content on recording fidelity. It is important to note the magnetic uniformity of the sediment used for the re-deposition experiments, as indicated by the consistency of AF demagnetization spectra, as well as by consistent ARM intensities when normalized by mass (Fig. 6a). Thus, any variation in the NRM/ARM ratio will be a result of variations in the efficiency of particle alignment during NRM acquisition. Water content is a key determinant of the DRM and PDRM intensity (Fig. 6b,c; Table 1), and therefore of the NRM/ARM ratio (Fig. 6d). When the water content is $40 \%$ or less, the NRM after addition of water is not significantly stronger than the NRM produced by dry deposition in zero-field (Fig. 6b). The NRM/ARM ratio for such samples is low $(\sim 0.1-0.2)$ because of the inefficient alignment of magnetic particles (Fig. 6d). As discussed above, the water content definition of Verosub et al. (1979) is not a true measure of water content in relation to sediment pore space; the high $\mathrm{H}_{2} \mathrm{O} \%$ values indicate that the sample was a wet slurry. Despite this definition, there is a key change in the magnetic recording quality at $\mathrm{H}_{2} \mathrm{O} \%=40-$ $50 \%$. When the water content exceeds $50 \%$, the NRM increases significantly after adding water and applying the $50-\mu \mathrm{T}$ field. The resulting NRM is so efficient that it is stronger than the ARM (Fig. 6b). For water contents $>45-50 \%$, the NRM/ARM ratio consistently exceeds 1.0 (Fig. 6d). These results indicate that there is a critical water content of $\sim 40 \%$ (which effectively reflects water saturation), above which the alignment efficiency of magnetic particles with the applied field improves significantly.

The final effect that we note is that the efficiency of NRM acquisition improves with longer exposure to an applied field. Samples that were left in the $50-\mu \mathrm{T}$ field in a water-logged state for $24 \mathrm{~h}$ have stronger NRMs than samples that were allowed to stand for $12 \mathrm{~h}$ or less (Fig. 6c,d). We did not allow samples to stand for longer periods of time to further test the effects of time exposure to a field for watersaturated sediments (such observations were reported for PDRM experiments by Otofuji et al. (1982)).

\subsection{Paleomagnetic recording fidelity of Chinese loess}

To address the question of how Chinese loess becomes magnetized, it is meaningful to compare the recording fidelity in our DRM and PDRM simulations with the long-term paleomagnetic recording fidelity of a range of Chinese loess sequences. In Fig. 7, we plot published paleomagnetic data from long stratigraphic sections onto equal area stereographic projections. We plot data from loess intervals only; we explicitly exclude paleosol data and intervals with elevated magnetic susceptibility values because we wish to better understand paleomagnetic recording in loess and we wish to avoid complications related to possible acquisition of an additional CRM associated with pedogenic formation of magnetite, maghemite and/or hematite. Whilst it has been argued that pedogenesis can affect loess

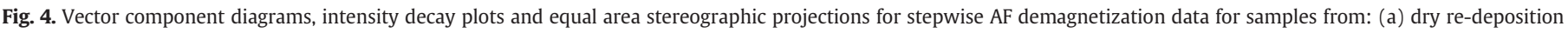

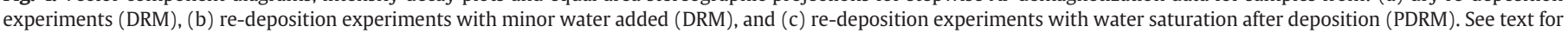
discussion. 
(a)

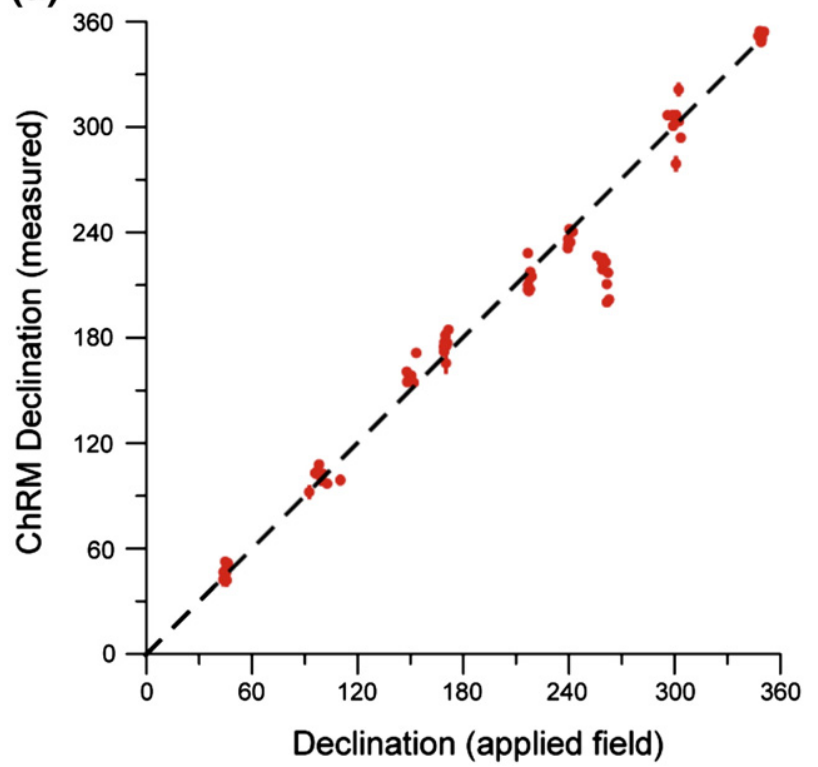

(b)

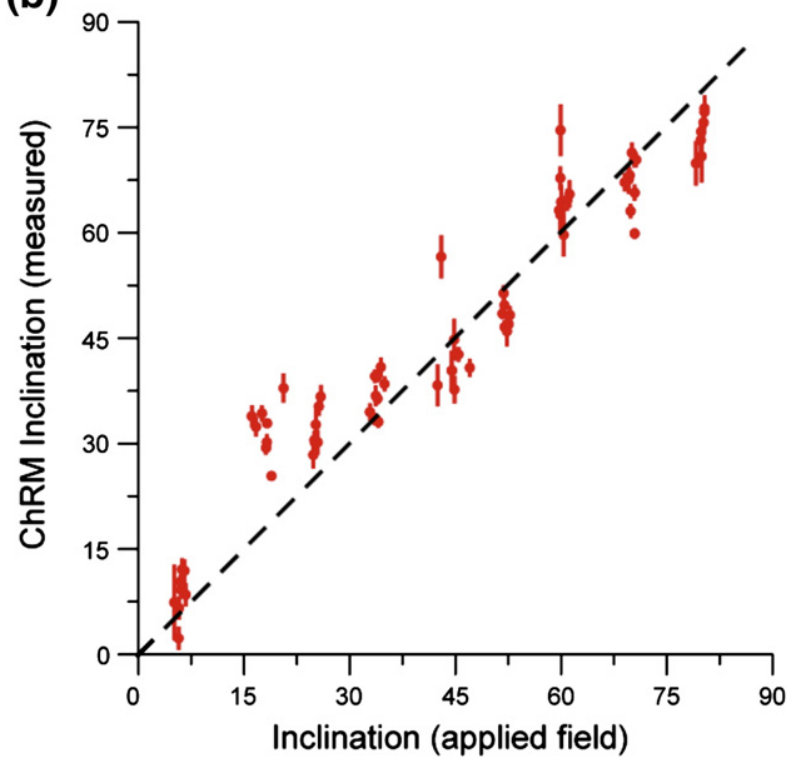

Fig. 5. Recording fidelity of a PDRM produced via dry deposition in zero-field followed by post-depositional water-saturation in a 50- $\mu \mathrm{T}$ field. (a) Calculated ChRM declination for re-deposited samples plotted versus the applied ambient field declination. (b) Calculated ChRM inclination for re-deposited samples plotted versus the applied ambient field inclination. Error bars represent the respective MAD values for the PCA fits for the ChRM determinations.

intervals as well as paleosols (e.g., Verosub et al., 1993), it is expected that the effects of pedogenesis will not be strong in loess intervals. We also exclude data from intervals that are interpreted to contain excursions and polarity transitions because our intention is to understand recording fidelity in non-transitional intervals. Data are plotted for the following stratigraphic intervals at the following localities: loess unit L1 (excluding sub-paleosol L1SS1) at Yichuan (Zhu et al., 2007), units L1, L2, L3, L4, L5, L6, L7, and the upper part of L8 (the problematical unit L9 was not included) at Sanmenxia (Wang et al., 2005), unit L1 (excluding sub-paleosol L1SS1 and the paleomagnetic excursion interpreted to lie within it) at Xifeng (Zhu et al., 2007), units L1 and L2 at Lingtai (Zhu et al., 2000), unit L1 at Baicaoyuan (Deng, 2008), units L1 and L2 at Weinan (Pan et al., 2002), and units L5, L6, L7, and the upper part of L8 at Baoji (Yang et al., 2007). For each location, we show the paleomagnetic data, the $95 \%$ cone of confidence about the mean direction, and the respective geocentric axial dipole (GAD) direction.

We aim to establish whether the paleomagnetic records for these distributed locations provide evidence for faithful recording of the time-averaged geomagnetic field. The time-averaged paleomagnetic direction sometimes coincides with the expected GAD direction (Fig. 7). However, the mean paleomagnetic direction for thick intervals of Chinese loess, within the respective 95\% confidence limits, often does not coincide with the expected GAD direction. In most cases, the inclinations are shallower than for the GAD field, and the mean declinations are generally deflected to the west of the expected GAD declination. Long paleomagnetic time series therefore indicate that Chinese loess can provide an accurate record of the timeaveraged geomagnetic field, but that degraded paleomagnetic recording is also widespread. When paleomagnetic data are included for the paleosol units within these sequences, the average paleomagnetic directions are often even shallower than for the loess-only data shown in Fig. 7. This suggests that CRM recording in paleosols merits further investigation, which is outside the scope of the present study.

\section{Discussion}

\subsection{Laboratory simulation of DRM}

Our initial experiments provide a simulation of DRM acquisition associated with eolian deposition under dry conditions. Faithful recording of the applied field declination, with systematically shallow inclinations (Figs. 2 and 3), is typical for a DRM. The measured DRM data (Fig. 3) follow the relationship given by the "inclination error formula" (King, 1955):

$\tan I_{o}=f \tan I_{f}$

where $I_{o}$ and $I_{f}$ are the observed and applied field inclinations, respectively, and $f$ is the so-called flattening factor. For the ChRM recorded in our re-deposition experiments, $f=0.42$, which is in the middle of the $f=0.2$ to 0.7 range reported for a DRM (e.g., King, 1955; Tauxe, 2005). Shallow paleomagnetic inclinations are apparently commonly recorded across the Chinese Loess Plateau (Fig. 7). It is therefore likely that a DRM is responsible for at least some of the NRMs recorded by the Chinese loess. However, our results also clearly demonstrate that a DRM cannot produce accurate recording of inclinations at the latitudes of the Chinese Loess Plateau (Fig. 3). Therefore, for locations, or for significant loess intervals at specific locations, where the mean paleomagnetic direction is indistinguishable from the expected GAD direction, another remanence acquisition mechanism must have been operating.

\subsection{Laboratory simulation of PDRM}

The importance of water in the acquisition of a remanent magnetization has long been recognised for a PDRM in general (e.g., Irving and Major, 1964) and for loess deposits in China (e.g., Burbank and Li, 1985; McIntosh, 1993) and Belgium (Hus and Geeraerts, 1986). All of the evidence from our experiments indicates that the postdepositional presence of water is crucial, above a threshold water content of $\sim 40 \%$ (which effectively corresponds to water saturation), for producing an efficient PDRM in eolian sediments. If a sedimentary sequence is magnetically homogeneous, and if the remanence was acquired under uniform conditions, one would expect the NRM/ARM ratio to provide a proxy estimate of the geomagnetic field strength (e.g., Tauxe, 1993). In our experiments, the sediment is magnetically homogeneous and the field strength was constant, therefore NRM/ ARM variations provide an indication of variations in the conditions under which the remanence was acquired. Our laboratory analyses 
(a)

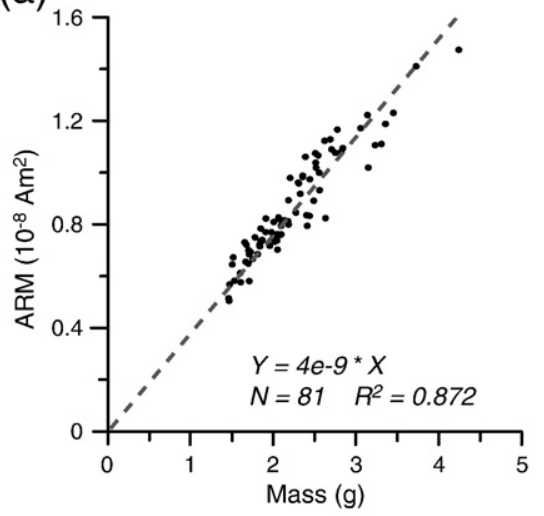

(c)

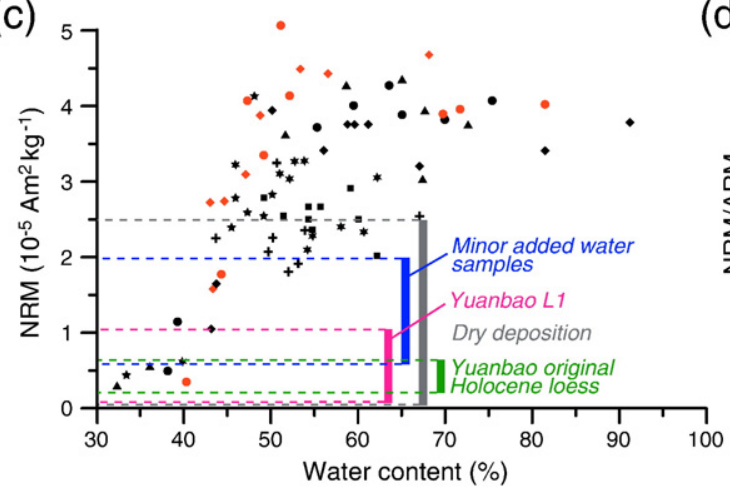

(b)

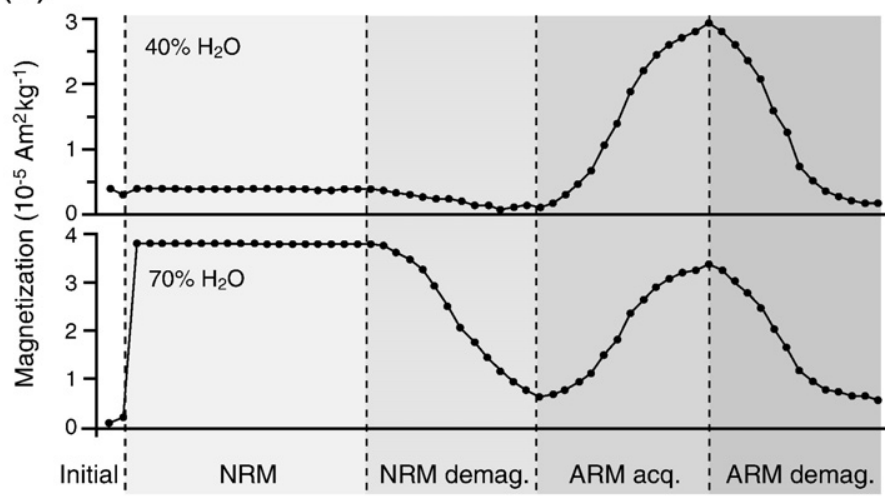

(d)

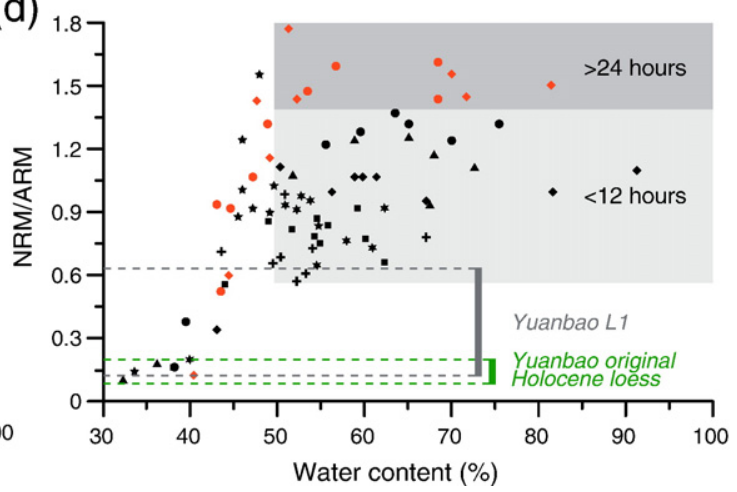

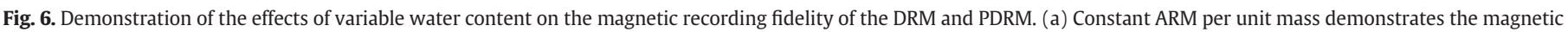

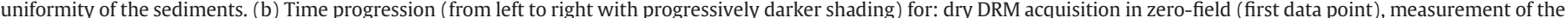

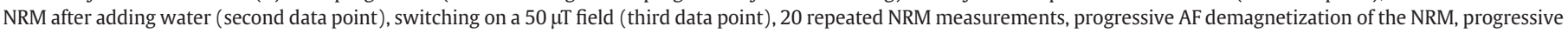

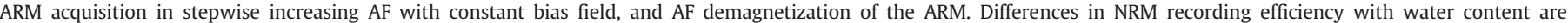

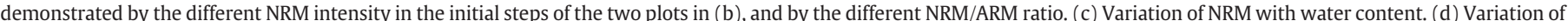

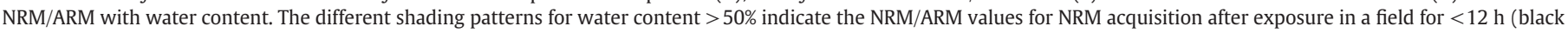

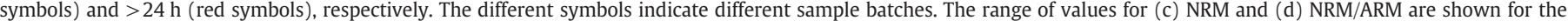
original Holocene loess parent material from Yuanbao and for the L1 loess from Yuanbao, along with the range of NRM values for the two sets of DRM experiments.

of consolidated Holocene and L1 loess samples from the Yuanbao section indicate that NRM/ARM ratios range between 0.08 and 0.65 (Table 1). If the NRM/ARM ratio of the Yuanbao loess can be related to the NRM/ARM ratio in our experiments (which they might not because of potentially large differences in magnetic particle alignment efficiency for different remanence acquisition mechanisms), and if our experiments provide any meaningful analogue for sedimentary conditions in the Chinese loess, the water content of the studied Chinese loess sediments can be inferred to have spanned the range between inefficient DRM acquisition ( $\mathrm{NRM} / \mathrm{ARM} \approx 0.1)$ and efficient PDRM acquisition (NRM/ARM $>0.4$ ). Comparison of data from Chinese loess in relation to our re-deposition experiments indicates that a mixed DRM and PDRM mechanism best explains a significant amount of the recorded paleomagnetic signal. However, the fact that short-period geomagnetic features are often recorded (e.g., Pan et al., 2002; Yang et al., 2007; Zhu et al., 2007) indicates that the PDRM must have shallow lock-in (Roberts and Winklhofer, 2004; Liu et al., 2008).

\subsection{Bioturbation?}

In marine environments, bioturbation is a key process that causes sediment irrigation and that allows the grain remobilization that is crucial to PDRM acquisition (e.g., Kent, 1973; Roberts and Winklhofer, 2004). It has been argued that a stirred remanent magnetization is a good analogue for a PDRM (Tucker, 1980; Payne and Verosub, 1982). The high NRM/ARM ratios of samples with water contents $>50 \%$ (Fig. 6d) indicate a good statistical alignment of magnetic particles with the applied field. Nevertheless, the PDRM acquisition process used here did not involve stirring and the NRM intensities, although strong, are not as strong as would be expected for a stirred remanent magnetization. We did not seek to simulate the effects of bioturbation by producing a stirred remanent magnetization because bioturbation is only considered to be important in paleosols or where mean annual precipitation exceeds $600 \mathrm{~mm} /$ year (Xiao et al., 1995). We therefore restrict our discussion about PDRM acquisition to the mechanical alignment of magnetic particles with the geomagnetic field in environments with water content $>40 \%$. We also note that Irving and Major (1964) successfully simulated a PDRM without bioturbation.

\subsection{Compaction-induced inclination flattening?}

Widespread inclination flattening in Chinese loess (Fig. 7) could be caused by DRM acquisition (Figs. 2 and 3 ) or compaction. Tauxe (2005) noted that both phenomena produce inclination flattening of the same form. Anson and Kodama (1987) argued that experimentally applied compaction pressures that produce inclination flattening are not applicable in natural sediments until depths of several hundred metres. In contrast, Arason and Levi (1990) observed noticeable compaction-induced inclination shallowing at depths of $60-85 \mathrm{~m}$. Several of the loess intervals from which data are plotted in Fig. 7 extend to maximum depths of $20 \mathrm{~m}$ (Baicaoyuan, Lingtai, Weinan, Xifeng and Yichuan), so compaction-induced inclination shallowing would not be expected. Data from Baoji and Sanmenxia extend down to loess units L7 or L8 at maximum depths of $50 \mathrm{~m}$. While there is 


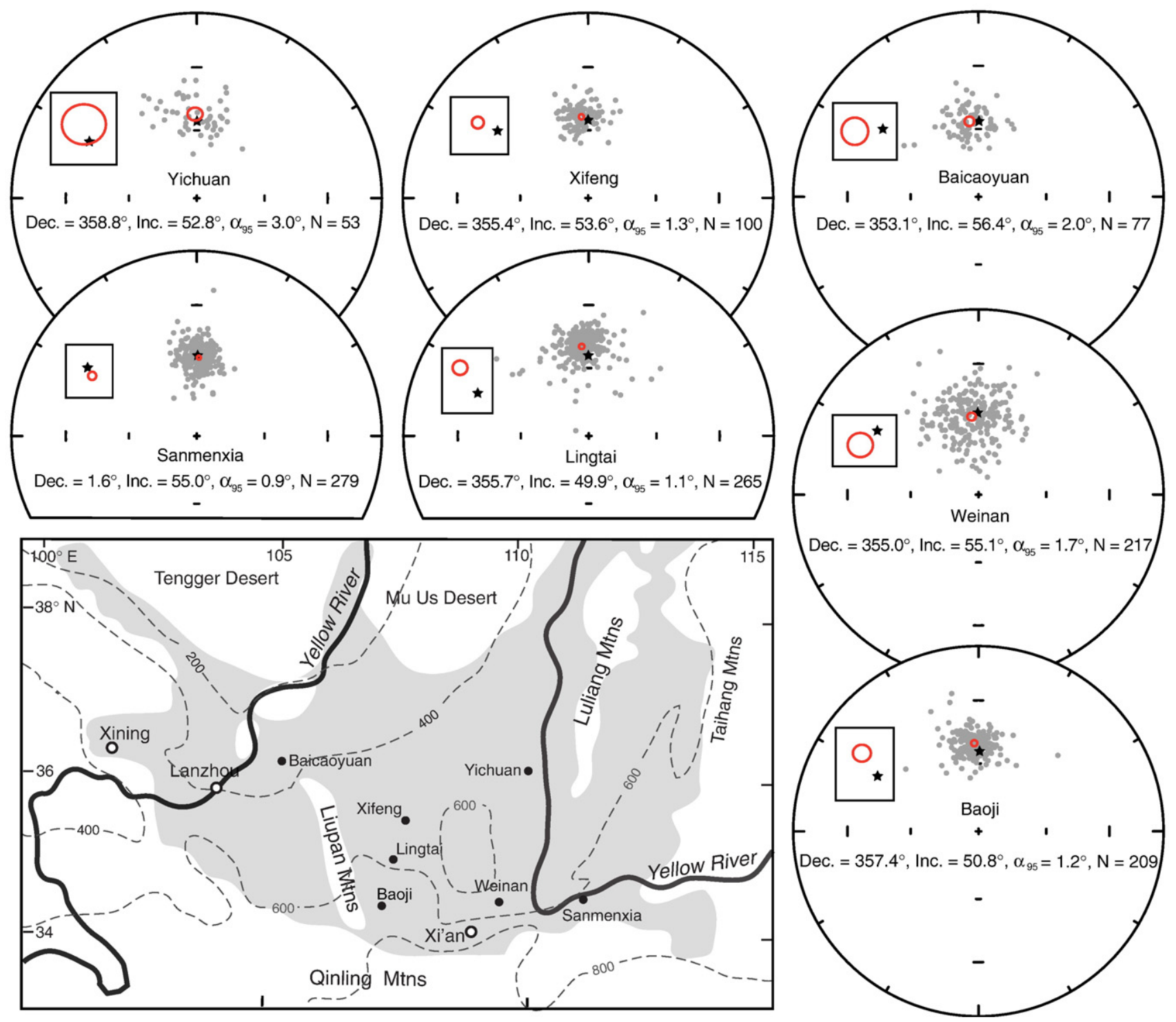

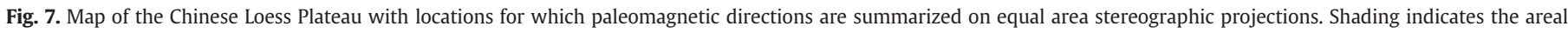

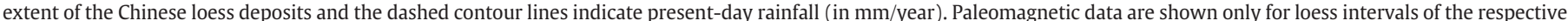

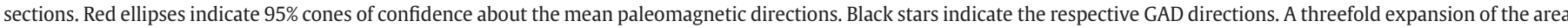

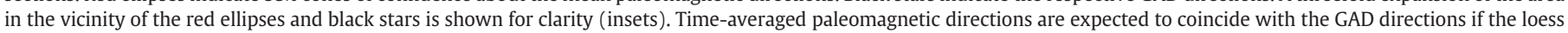

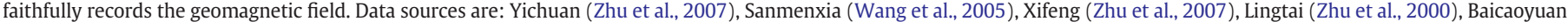
(Deng et al., 2008), Weinan (Pan et al., 2002), and Baoji (Yang et al., 2007). See text for details of the stratigraphic intervals from which data are plotted.

significant inclination flattening at Baoji, the mean inclination at Sanmenxia is steeper than the GAD inclination. In contrast, inclination shallowing is more common for shallow sampling intervals (Fig. 7). These observations are difficult to reconcile with compaction-induced inclination shallowing. Application of the elongation-inclination method (Tauxe, 2005) to correct for inclination shallowing also consistently yields unrealistically steep inclinations at the respective site latitudes. We therefore conclude that the observed inclination errors (Fig. 7) are more reasonably explained by DRM recording than by compaction.

\subsection{DRM and PDRM remanence intensities}

Inspection of Table 1 reveals a conundrum concerning the NRM intensity of the loess parent material that was re-deposited to produce the simulated DRM and PDRM. The NRM of the original loess is weak and ranges between 2.45 and $6.6 \times 10^{-6} \mathrm{Am}^{2} \mathrm{~kg}^{-1}$. In contrast, the mean intensity of the simulated DRM is stronger than the upper range of loess NRM values (at $9.21 \times 10^{-6} \mathrm{Am}^{2} \mathrm{~kg}^{-1}$ ), as is the entire range of PDRM intensities. This suggests that the simulated DRM and PDRM are both more efficient than the real NRM acquisition mechanism. It should, however, be borne in mind that the NRM of natural samples will contain a viscous component that has weakened the NRM from its original intensity. A DRM therefore remains a likely candidate as the NRM acquisition mechanism for Chinese loess. In contrast, the simulated PDRM is too efficient in terms of both directional recording fidelity and remanence intensity to be viable as a dominant mechanism for magnetizing the Chinese loess. Conversely, however, the degree of inclination shallowing evident in Fig. 7 is not as large as in our simulated DRM (Figs. 2 and 3). It is therefore highly likely that some water was present during remanence acquisition for significant stratigraphic intervals of the Chinese loess to produce the only partially degraded paleomagnetic records in Fig. 7. A timevarying mixture between PDRM and DRM mechanisms therefore 
seems likely. If a PDRM has been in operation, then some aspect of loessification is likely to have given rise to a decrease in remanence intensity over time that we have not been able to reproduce in our laboratory re-deposition experiments. Future work is needed to understand this.

\subsection{Loess deposition and rainfall on the Chinese Loess Plateau}

The Chinese Loess Plateau had an arid and dusty environment during glacial periods, but preservation of loess after deposition is not guaranteed. Any deposited loess would have been vulnerable to deflation and re-suspension. Addition of moisture, through rainfall, would provide cohesion to the sediment and would enhance resistance to deflation of the loess substrate. However, the probability of erosion will be increased by desiccation and strong winds. Unlike marine sediments, which are generally expected to undergo reasonably continuous deposition, loess has been demonstrated to undergo episodic and highly variable deposition on glacial/interglacial timescales and sub-orbital timescales, with non-deposition or erosion being common (e.g., Stevens et al., 2006, 2007). On annual timescales, dust delivery is not uniform and is associated with extreme weather events, with large dust outbreaks from loess source regions being most frequent in spring (Roe, 2009). Rainfall would not have been abundant on the Chinese Loess Plateau during glacial times, but rainfall after a dust deposition event is likely to have aided preservation of the deposited dust. Crucially, our results indicate that moisture is required for loess to faithfully record geomagnetic field variations. The fact that inclination errors are common in Chinese loess (Fig. 7) might suggest that water contents were often below the critical $\sim 40 \%$ threshold required to produce a PDRM and that a DRM must be responsible for a significant amount of the paleomagnetic signal recorded by the Chinese loess. Nevertheless, time-averaged paleomagnetic directions that are indistinguishable from the expected GAD field direction at some localities and NRM/ARM ratios that exceed 0.4 indicates that in other cases, a PDRM must be responsible for a significant amount of the paleomagnetic signal recorded by the Chinese loess. We therefore conclude that the Chinese loess is magnetized by a combination of DRM and PDRM mechanisms, with water content providing the key control on which remanence acquisition mechanism is dominant. We note, however, that there is no particular correlation between long-term paleomagnetic recording quality and the present day rainfall distribution shown in Fig. 7. Loess sequences from the more arid northern parts of the Chinese Loess Plateau are often targeted for paleomagnetic studies to avoid pedogenic effects. It should be noted that reduced rainfall in these areas probably also contributes to reduced PDRM recording fidelity. The complex combination of remanence acquisition mechanisms, including DRM, PDRM, and CRM mechanisms, and their likely variation through time, not to mention episodic deposition/preservation, provides a significant complication for interpretation of shortperiod geomagnetic fluctuations from the Chinese loess. Regardless, efficient PDRM lock-in is likely to be associated with moisture availability, and the recording of short-period features such as geomagnetic excursions (e.g., Pan et al., 2002; Yang et al., 2007; Zhu et al., 2007) means that the lock-in depth must be shallow (cf. Roberts and Winklhofer, 2004).

\section{Conclusions}

To address the lack of a convincing explanation for how Chinese loess becomes magnetized, we conducted laboratory re-deposition experiments using disaggregated loess. We simulated dry deposition of eolian sediments to produce a DRM without post-depositional modification. The simulated DRM provides a faithful record of the applied field declination, but with systematic inclination flattening. Post-depositional addition of minor water slightly improves recording of the applied field, but inclination flattening persists. We then simulated a PDRM by adding water in varying concentrations after dry deposition of eolian sediments. Reliable recording of the applied field occurs when the sediment is water-saturated. We also synthesized paleomagnetic data from Chinese loess sequences to test actual paleomagnetic recording against our laboratory simulations. Time-averaged paleomagnetic directions for loess sequences are often indistinguishable from the expected geocentric axial dipole (GAD) field, but in other cases inclinations are shallower than for a GAD field. We therefore conclude that the Chinese loess is magnetized by a combination of DRM and PDRM mechanisms, with water content providing the dominant control on the remanence acquisition mechanism. Where pedogenesis causes growth of magnetite, maghemite and/or hematite through the stable single domain blocking volume, an additional chemical remanent magnetization (CRM) will occur. The magnetization of Chinese loess therefore appears to be controlled by a complex, time-varying combination of DRM, PDRM and CRM mechanisms. This complexity has important consequences for the paleomagnetic recording fidelity of the Chinese loess, particularly for determination of short-period geomagnetic fluctuations, although PDRM lock-in is likely to be shallow because short-period features such as geomagnetic excursions are often recorded in the Chinese loess.

\section{Acknowledgements}

Xiang Zhao is supported by a Dorothy Hodgkin Postgraduate Award, which is funded by Hutchison Whampoa Limited and the U.K. Natural Environment Research Council. We are grateful to Rui Zhang for providing data from Xifeng and Yichuan, Rixiang Zhu for data from Weinan and Lingtai, Chenglong Deng for data from Baicaoyuan, and Tianshui Yang for data from Baoji. We also thank Baojun Zhang for assistance in the field at Yuanbao and Ray Collins and John Hewitt for their assistance in building the eolian dust deposition simulator. Constructive review comments from Gregg McIntosh and two anonymous reviewers helped to improve the paper.

\section{References}

Anson, G.L., Kodama, K.P., 1987. Compaction-induced inclination shallowing of the post-depositional remanent magnetization in a synthetic sediment. Geophys. J. R. Astron. Soc. 88, 673-692.

Arason, P., Levi, S., 1990. Compaction and inclination shallowing in deep-sea sediments from the Pacific Ocean. J. Geophys. Res. 95, 4501-4510.

Burbank, D.W., Li, J.J., 1985. Age and palaeoclimatic significance of the loess of Lanzhou, north China. Nature 316, 429-431.

Deng, C., 2008. Paleomagnetic and mineral magnetic investigation of the Baicaoyuan loess-paleosol sequence of the western Chinese Loess Plateau over the last glacialinterglacial cycle and its geological implications. Geochem. Geophys. Geosyst. 9, Q04034. doi:10.1029/2007GC001928.

Guo, Z., Ruddiman, W.F., Hao, Q., Wu, H., Qiao, Y., Zhu, R., Peng, S., Wei, J., Yuan, B., Liu, T., 2002. Onset of Asian desertification by $22 \mathrm{Myr}$ ago inferred from loess deposits in China. Nature 416, 159-163.

Heller, F., Liu, T.S., 1982. Magnetostratigraphical dating of loess deposits in China. Nature 300, 431-433.

Heller, F., Liu, T.S., 1984. Magnetism of Chinese loess deposits. Geophys. J. R. Astron. Soc. 77, 125-141.

Heslop, D., Langereis, C.G., Dekkers, M.J., 2000. A new astronomical time scale for the loess deposits of Northern China. Earth Planet. Sci. Lett. 184, 125-139.

Hus, J.J., Geeraerts, R., 1986. Palaeomagnetic and rock magnetic investigation of Late Pleistocene loess deposits in Belgium. Phys. Earth Planet. Inter. 44, 21-40.

Irving, E., Major, A., 1964. Post-depositional detrital remanent magnetization in a synthetic sediment. Sedimentology 3, 135-143.

Kent, D.V., 1973. Post-depositional remanent magnetization in deep-sea sediment. Nature 246, 32-34.

King, R.F., 1955. The remanent magnetism of artificially deposited sediments. Mon. Not. R. Astron. Soc. Geophys. Suppl. 7, 115-134.

Kirschvink, J.L., 1980. The least-squares line and plane and the analysis of palaeomagnetic data. Geophys. J. R. Astron. Soc. 62, 699-718.

Kukla, G., Heller, F., Liu, X.M., Xu, T.C., Liu, T.S., An, Z.S., 1988. Pleistocene climates in China dated by magnetic susceptibility. Geology 16, 811-814.

Liu, T.S., et al., 1985. Loess and the Environment. China Ocean Press, Beijing. 251 pp.

Liu, X.M., Liu, T.S., Xu, T.C., Liu, C., Chen, M.Y., 1988. The Chinese loess in Xifeng, I. The primary study on magnetostratigraphy of a loess profile in Xifeng area, Gansu province. Geophys. J. 92, 345-348. 
Liu, Q., Banerjee, S.K., Jackson, M.J., Deng, C., Pan, Y., Zhu, R., 2005. Inter-profile correlation of the Chinese loess/paleosol sequences during Marine Oxygen Isotope Stage 5 and indications of pedogenesis. Quat. Sci. Rev. 24, 195-210.

Liu, Q., Roberts, A.P., Rohling, E.J., Zhu, R., Sun, Y., 2008. Post-depositional remanent magnetization lock-in and the location of the Matuyama-Brunhes geomagnetic reversal boundary in marine and Chinese loess sequences. Earth Planet. Sci. Lett. 275, 102-110.

McIntosh, G., 1993. Post-depositional detrital remanent magnetisation in Chinese loess: preliminary results of laboratory experiments. Geol. Carpath. 44, 335-338.

Otofuji, Y., Katsura, I., Sasajima, S., 1982. Decay of a post-depositional remanent magnetization in wet sediments due to the effect of drying. Geophys. J. R. Astron. Soc. 70, 191-203.

Pan, Y., Zhu, R., Liu, Q., Guo, B., Yue, L., Wu, H., 2002. Geomagnetic episodes of the past 1.2 Myr recorded in Chinese loess. Geophys. Res. Lett. 29, 1282. doi:10.1029/ 2001 GL014024.

Payne, M.A., Verosub, K.L., 1982. The acquisition of post-depositional detrital remanent magnetization in a variety of natural sediments. Geophys. J. R. Astron. Soc. 68, 625-642.

Roberts, A.P., Winklhofer, M., 2004. Why are geomagnetic excursions not always recorded in sediments? Constraints from post-depositional remanent magnetization lock-in modeling. Earth Planet. Sci. Lett. 227, 345-359.

Roe, G., 2009. On the interpretation of Chinese loess as a paleoclimate indicator. Quat. Res. 71, 150-161.

Rutter, N., Ding, Z., Evans, M.E., Wang, Y., 1990. Magnetostratigraphy of the Baoji loesspaleosol section in the north-central China Loess Plateau. Quat. Int. 7/8, 97-102.

Spassov, S., Heller, F., Evans, M.E., Yue, L., von Dobeneck, T., 2003. A lock-in model for the complex Matuyama-Brunhes boundary record of the loess/paleosol sequence at Lingtai (Central Chinese Loess Plateau). Geophys. J. Int. 155, 350-366.

Stevens, T., Armitage, S.J., Lu, H., Thomas, D.S.G., 2006. Sedimentation and diagenesis of Chinese loess: implications for the preservation of continuous, high-resolution climate records. Geology 34, 849-852.

Stevens, T., Thomas, D.S.G., Armitage, S.J., Lunn, H.R., Lu, H., 2007. Reinterpreting climate proxy records from late Quaternary Chinese loess: a detailed OSL investigation. Earth Sci. Rev. 80, 111-136.

Tauxe, L., 1993. Sedimentary records of relative paleointensity of the geomagnetic field: theory and practice. Rev. Geophys. 31, 319-354.
Tauxe, L., 2005. Inclination flattening and the geocentric axial dipole hypothesis. Earth Planet. Sci. Lett. 233, 247-261.

Tauxe, L., Herbert, T., Shackleton, N.J., Kok, Y.S., 1996. Astronomical calibration of the Matuyama-Brunhes boundary; consequences for magnetic remanence acquisition in marine carbonates and the Asian loess sequences. Earth Planet. Sci. Lett. 140, 133-146.

Tucker, P., 1980. Stirred remanent magnetization: a laboratory analogue of postdepositional realignment. J. Geophys. 48, 153-157.

Verosub, K.L., Ensley, R.A., Ulrick, J.S., 1979. The role of water content in the magnetization of sediments. Geophys. Res. Lett. 6, 226-228.

Verosub, K.L., Fine, P., Singer, M.J., TenPas, J., 1993. Pedogenesis and paleoclimate: interpretation of the magnetic susceptibility record of Chinese loess-paleoso sequences. Geology 21, 1011-1014.

Wang, X., Løvlie, R., Yang, Z., Pei, J., Zhao, Z., Sun, Z., 2005. Remagnetization of Quaternary eolian deposits: a case study from SE Chinese Loess Plateau. Geochem. Geophys. Geosyst. 6, Q06H18. doi:10.1029/2004GC000901.

Wang, X., Yang, Z., Løvlie, R., Sun, Z., Pei, J., 2006. A magnetostratigraphic reassessment of correlation between Chinese loess and marine oxygen isotope records over the last 1.1 Ma. Phys. Earth Planet Inter. 159, 109-117.

Xiao, J., Porter, S.C., An, Z., Kumai, H., Yoshikawa, S., 1995. Grain size of quartz as an indicator of winter monsoon strength on the Loess Plateau of central China during the last 130, 000 yr. Quat. Res. 43, 22-29.

Yang, T., Hyodo, M., Yang, Z., Fu, J., 2007. Two geomagnetic excursions during the Brunhes Chron recorded in Chinese loess-paleosol sediments. Geophys. J. Int. 171 104-114.

Zhou, L.P., Shackleton, N.J., 1999. Misleading positions of geomagnetic reversal boundaries in Eurasian loess and implications for correlation between continental and marine sedimentary sequences. Earth Planet. Sci. Lett. 168, 117-130.

Zhou, L.P., Oldfield, F., Wintle, A.G., Robinson, S.G., Wang, J.T., 1990. Partly pedogenic origin of magnetic variations in Chinese loess. Nature 346, 737-739.

Zhu, R., Guo, B., Pan, Y., Liu, Q., Zeman, A., Suchy, V., 2000. Reliability of geomagnetic secular variations recorded in a loess section at Lingtai, north-central China. Sci. China D 43, 1-9.

Zhu, R., Zhang, R., Deng, C., Pan, Y., Liu, Q., Sun, Y., 2007. Are Chinese loess deposits essentially continuous? Geophys. Res. Lett. 34, L17306. doi:10.1029/2007GL030591. 